\title{
Levels of vascular endothelial growth factor are elevated in the vitreous of patients with subretinal neovascularisation
}

John A Wells, Rachna Murthy, Rakesh Chibber, Alistair Nunn, Pia A Molinatti, Eva M Kohner, Zdenek J Gregor

\begin{abstract}
Background-Vascular endothelial growth factor (VEGF) has been shown to play a major role in intraocular neovascularisation in ischaemic retinal diseases. Subretinal neovascularisation is an important cause of central visual loss, but little is known about the role of this growth factor in its pathogenesis. The aim of this study was to investigate the possible role of VEGF in the development of subretinal neovascularisation.
\end{abstract}

Methods-Undiluted vitreous samples were obtained from patients undergoing vitrectomy for removal of non-agerelated subfoveal neovascular membranes (SFNM). For comparison vitreous from patients undergoing vitrectomy for idiopathic full thickness macular holes (FTMH) and proliferative diabetic retinopathy (PDR) was used. Indirect enzyme linked immunosorbent assay (ELISA), with an antibody directed against the conserved $\mathbf{N}$-terminal region of human VEGF V65 $_{16}$, was used to determine vitreous levels of VEGF. The growth factor was also localised in the vitreous of patients with SFNM by western blot analysis.

Results-The mean (SE) VEGF concentration in the vitreous of patients with SFNM was $27.78(2.22) \quad \mathrm{ng} / \mathrm{ml}(\mathrm{n}=8)$, FTMH was $16.62(0.9) \mathrm{ng} / \mathrm{ml}(\mathrm{n}=18)$, and PDR was $37 \cdot 77(3 \cdot 28) \mathrm{ng} / \mathrm{ml}(\mathrm{n}=16)$. The differences between the PDR group and SFNM group versus the FTMH group were both significant $(p=0.0001$ and $p=0.0015)$ as analysed by the Wilcoxon rank sum test).

Conclusions-Vitreous levels of VEGF are significantly elevated in eyes with nonage-related subretinal neovascularisation compared with eyes with FTMH but not as elevated as in PDR. This suggests that VEGF is involved in subretinal angiogenesis.

(Br f Ophthalmol 1996; 80: 363-366)

Postgraduate Medical

School, Hammersmith

Hospital, London

R Murthy

R Chibber

A Nunn

P A Molinatti

E M Kohner

Correspondence to: Mr Z J Gregor, Moorfields Eye Hospital, City Road, London ECIV 2PD.

Accepted for publication 19 January 1996 tion. Results from recent studies suggest that vascular endothelial growth factor (VEGF), also known as vascular permeability factor $(\mathrm{VPF})^{2}$ or vasculotropin, ${ }^{3}$ plays a major role in the development of intraocular neovascularisation. ${ }^{4}$ VEGF is a secreted 46 $\mathrm{kDa}$ polypeptide that has four homodimeric forms as a result of alternative splicing (giving peptides of 206,189,165, and 121 amino acids). ${ }^{6}$ It is a potent and specific mitogen for vascular endothelial cells. ${ }^{7}$ The expression of VEGF is upregulated by hypoxia, transforming growth factor $\beta$ (TGF $\beta$ ), and by intraocular inflammation. ${ }^{8-10}$ Consistent with its endothelial cell mitogenicity, VEGF has also been shown to promote new capillary formation when added on the chick chorioallantoic membrane. ${ }^{6}$ Besides angiogenic activity, VEGF also displays the physiological function of increasing the permeability of capillary microvessels to different macromolecules. ${ }^{11}$

The concentration of VEGF has been shown to decrease in the eye after successful laser treatment for proliferative retinopathies and when neovascularisation becomes inactive without treatment. ${ }^{4}$ Additionally, the administration of antibody directed against VEGF has been shown to inhibit neovascularisation in retinal ischaemia. ${ }^{12}$ Thus, VEGF would seem to fulfil the criteria for the long sought angiogenic factor in that its concentration in the eye is elevated in ischaemia, it is diffusible into the vitreous and anterior chamber, it stimulates endothelial cell proliferation, and its concentration significantly falls with involution of active new vessels.

While there seems to be convincing evidence that VEGF has an important role in the development of preretinal, optic disc, and iris neovascularisation in ischaemic retinopathies, little is known regarding the potential role of VEGF in the pathogenesis of subretinal neovascularisation. Subfoveal neovascular membranes (SFNM) are often devastating to central vision and have generally been considered untreatable in terms of restoring central vision because laser treatment permanently destroys foveal photoreceptors. However, Thomas and Kaplan demonstrated that surgical excision and restoration of visual acuity was possible in selected cases of SFNM. ${ }^{13}$ While the treatment of SFNM may be advancing, our understanding of the pathogenetic processes is still incomplete, especially with regard to the role of growth factors in subretinal angiogenesis. The purpose of this report is to describe our findings of elevated levels of VEGF in the vitreous of patients undergoing vitrectomy for removal of non-age-related subfoveal neovascularisation. 


\section{Materials and methods}

\section{STUDY POPULATION}

Patients referred to the retinal diagnostic department at Moorfields Eye Hospital with a diagnosis of non-age-related SFNM had a complete ophthalmic examination including best corrected Snellen visual acuity, dilated fundus examination, and stereoscopic colour fundus photography and fluorescein angiography. All patients were judged to have SFNM anterior to the retinal pigment epithelium (type 2 SFNM according to the classification of Gass $^{14}$ ). No patients had drusen in either eye or any other evidence of age-related macular degeneration. After confirmation that the SFNM was the cause of the patient's visual loss, an extensive explanation of the relative risks and benefits of vitrectomy and removal of the SFNM was given to each patient. Those patients who elected to undergo surgery were included in the study.

The study consisted of eight patients, seven women and one man, whose mean age was 31.5 years (range $17-50$ years). The underlying diagnoses consisted of idiopathic SFNM (three cases), punctate inner choroidopathy (PIC) (two cases), multifocal inner choroidopathy (MIC) (one case), quiescent sympathetic ophthalmitis (one case), and traumatic choroidal rupture (one case). The mean duration of the SFNM preoperatively was 6 months (range 3-16 months). The comparison group consisted of 18 patients with idiopathic full thickness macular hole (FTMH) and of 16 patients with advanced proliferative diabetic retinopathy (PDR) and traction retinal detachment involving the macula, all of whom underwent vitrectomy. The group of patients with macular holes consisted of 13 women and five men with a mean age of 62 years (range 24-77) and with no evidence of age-related macular degeneration in either eye. Of the diabetic patients, seven were women and nine were men and their mean age was 42 years (range 33-65).

\section{VITREOUS SAMPLES}

All study and comparison cases had vitreous samples obtained intraoperatively in the same manner. A standard three port pars plana vitrectomy was performed in all cases. Before turning on the intravitreal infusion, an undiluted sample $(0.5-1.0 \mathrm{ml})$ of vitreous was obtained by aspiration into a $2 \mathrm{ml}$ syringe attached to the vitreous cutter. The syringe with the sample was then frozen at $-70^{\circ} \mathrm{C}$ until it was required for analysis. The operation was then completed in the usual fashion.

\section{Laboratory methods}

ELISA FOR VEGF

Enzyme linked immunosorbent assay (ELISA) of undiluted vitreous samples and human recombinant $V_{E G F}$ ( $R$ \& D Systems, Abingdon) was carried out to quantitate the levels of VEGF. The samples were dissolved in bicarbonate buffer, $\mathrm{pH} 9 \cdot 6$, and then coated on 96 well microtitre plates (ICN Biomedicals, Thame) and incubated overnight at room temperature. The wells were then washed with 20 mM TRIS pH 7.5, $0.05 \mathrm{M} \mathrm{NaCl}$, and $0.05 \%$ Tween-20 (TRIS buffered saline, TBST) and blocked by incubation for 1 hour at $37^{\circ} \mathrm{C}$ with TBST containing 3\% bovine serum albumin (BSA) (Sigma, Poole) and 1:50 normal goat serum (NGS) (Sigma). After washing, polyclonal anti-VEGF 165 antibody (kind gift of Dr $\mathrm{H}$ Weich, Department of Gene Expression, Braunschweig, Germany) diluted 1:1000 in TBST was added and the plates incubated for 1 hour at $37^{\circ} \mathrm{C}$. After washing biotinylated anti-rabbit IgG (final dilution 1:20000 in TBST containing $1 \%$ BSA) was added. After 1 hour of incubation at $37^{\circ} \mathrm{C}$ the wells were washed and extravidin alkaline phosphatase (final dilution 1:20000 in TBST containing $1 \%$ BSA) added. The reaction was developed utilising $p$-nitrophenyl phosphate (pNPP, Sigma) as a colorimetric substrate, and the absorbance was measured at $405 \mathrm{~nm}$ after 1 hour, using an automated plate reader (Novo Biolabs, Nottingham).

\section{WESTERN BLOT ANALYSIS}

Once thawed the vitreous samples were denatured in sample buffer containing $62 \mathrm{mM}$ TRIS-HCl, $\mathrm{pH} 6.8 ; 10 \% \mathrm{v} / \mathrm{v}$ glycerol; $2 \%$ sodium dodecyl sulphate (SDS); 5\% mercaptoethanol; $0.001 \% \mathrm{w} / \mathrm{v}$ bromophenol blue). Samples were heated at $95^{\circ} \mathrm{C}$ for 4 minutes and then subjected to SDS polyacrylamide gel electrophoresis (SDS-PAGE) using a 10\% gel. Proteins were transferred to Hybond-ECL membrane (Amersham, Aylesbury) and the presence of VEGF detected by immunoblotting. The membrane was blocked with 5\% BSA in TBST. All antibody incubations were performed in $1 \%$ BSA in TBST. Antibody for VEGF $_{165}$ was used at a 1:1000 dilution. Primary antibody-antigen complex was detected with anti-rabbit IgG horseradish peroxidase conjugate $(1: 10000)$ with ECL western blotting analysis system (Amersham).

\section{PROTEIN MEASUREMENT}

Total protein was determined by using the bicinchioninic acid method (Sigma, Dorset).

\section{STATISTICAL ANALYSIS}

The levels of VEGF in the different groups were compared by the Wilcoxon rank sum test.

Table 1 Precision of the ELISA for vascular endothelial growth factor (VEGF)

\begin{tabular}{llllll}
\hline \multirow{2}{*}{$\begin{array}{l}\text { Sample } \\
\text { No }\end{array}$} & \multicolumn{2}{l}{ Within assay $(n=5)$} & & \multicolumn{2}{l}{ Between run $(n=5)$} \\
\cline { 2 - 3 } \cline { 5 - 6 } \cline { 5 - 6 }$(S D)^{\star}$ & $C V(\%)$ & & Mean $(S D)^{\star}$ & $C V(\%)$ \\
\hline 1 & $1 \cdot 127(0.0063)$ & 5.88 & & $1.0279(0.0064)$ & 6.2 \\
3 & $2.536(0.0131)$ & 5.20 & & $2.5944(0.0124)$ & 4.8 \\
& $5.354(0.0402)$ & 7.51 & & $5.1288(0.0333)$ & 6.5 \\
\hline
\end{tabular}

$\star^{\star} \mathrm{ng} / \mathrm{ml}$ of VEGF. $\mathrm{CV}=$ coefficient of variation. 


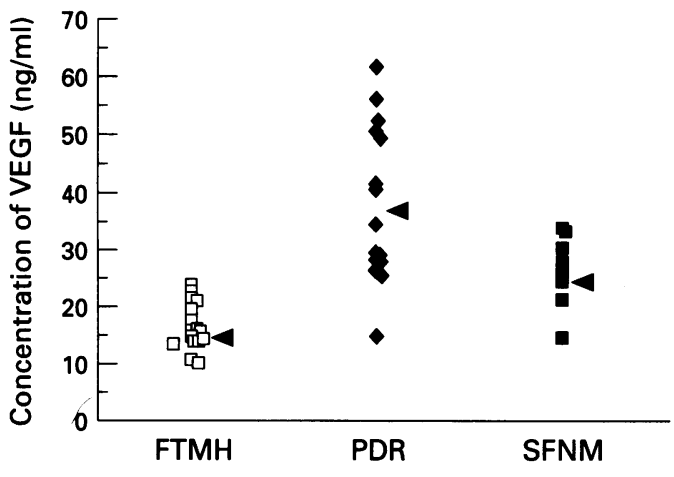

Figure 1 Vascular endothelial growth factor (VEGF) concentration in vitreous of patients undergoing vitrectomy for removal of non-age-related subfoveal neovascular membranes (SFNM), idiopathic full thickness macular holes (FTMH), and proliferative diabetic retinopathy (PDR). The mean concentrations of VEGF (arrowhead) in vitreous from SFNM, PDR, and FTMH groups were $27.8(2 \cdot 22), 37.77(3.28)$, and $16.62(0.9) \mathrm{ng} / \mathrm{ml}$, respectively.

\section{Results}

The level of VEGF in the vitreous was detected with a specific antibody using ELISA with sensitivity of $0.5 \mathrm{ng} / \mathrm{ml}$. The intra-assay variation for this ELISA was $5 \cdot 9-7 \cdot 5 \%$ and the interassay variation was $4 \cdot 8-6^{\circ} 5 \%$ (Table 1 ). The mean level (SE) of VEGF in the SFNM group was $27 \cdot 78(2 \cdot 22) \mathrm{ng} / \mathrm{ml}(\mathrm{n}=8)$ and in the FTMH group was $16.62(0.9) \mathrm{ng} / \mathrm{ml}(\mathrm{n}=18)$. The difference between these two groups was significant $(p=0.001$, Wilcoxon rank sum test).

The levels of VEGF were highest in eyes with PDR with a mean level of $37 \cdot 77(3.28)$ $\mathrm{ng} / \mathrm{ml}(\mathrm{n}=16)$. These levels were significantly higher than in FTMH group $(p=0.0001)$ and the SFNM group $(p=0.028)$. The difference between all three groups is illustrated graphically in Figure 1. The presence of VEGF was also confirmed by western blot analysis. Vitreous samples denatured in sample buffer were separated by SDS-PAGE on $10 \%$ gel. An immunoreactive band corresponding to molecular weight of $42 \mathrm{kDa}$ was detected in the SFNM and FTMH samples (Fig 2). In most but not all the patients, the levels of VEGF

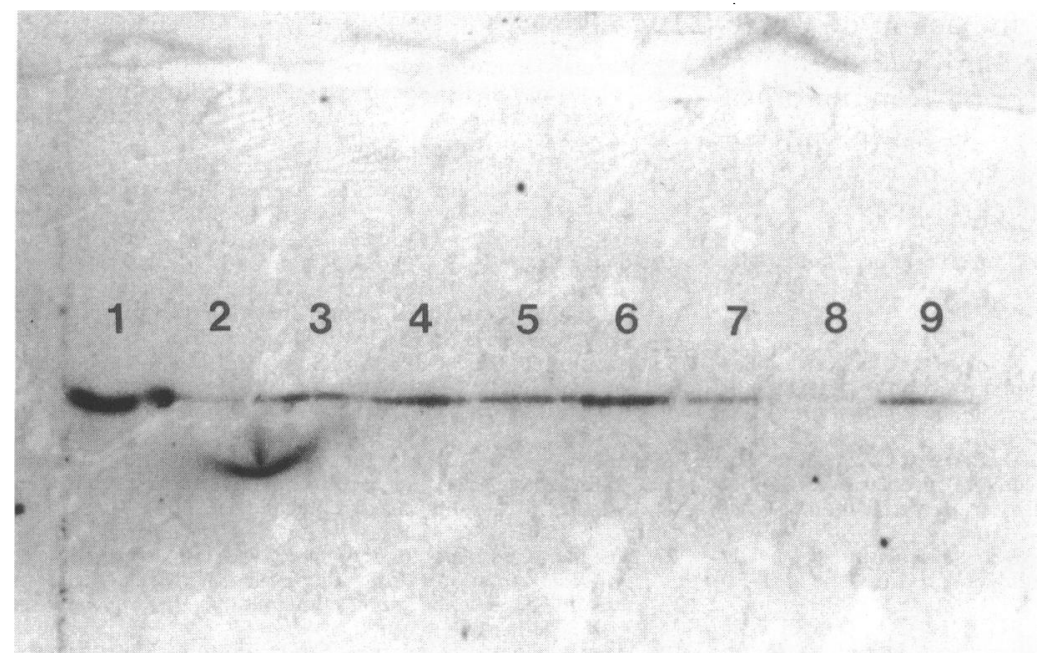

Figure 2 Western blot analysis using specific VEGF ${ }_{165}$ antibody of vitreous from SFNM (lanes 2-5), FTMH group (lanes 6-9), and 2 ng of human recombinant VEGF 165 (lane 1): $12 \cdot 5 \mu l$ (approximately $1.5 \mu g$ of protein) of vitreous was used for the experiment. The proteins were separated by SDS-PAGE run at 4\% for the stacking gel and $10 \%$ for the running gel and then transferred to Hybond-ECL membrane. determined by ELISA, compared well with those determined by western blot analysis and scanning densitometry (data not shown). This was perhaps expected since we lacked an internal control to make sure that an equal amount of protein from the vitreous sample was loaded per well. For this reason the western blot analysis was used mainly for qualitative and not quantitative determination of vitreous levels of VEGF.

\section{Discussion}

Subretinal neovascularisation is a devastating complication of macular diseases, the most common being age-related macular degeneration (ARMD). Most theories of the subretinal neovascular process implicate the occurrence of breaks in Bruch's membrane as the initial step. It is likely that once these breaks occur a reparative process, similar to wound healing, is initiated that stimulates endothelial cell proliferation and fibroglial scar formation. ${ }^{15} 16$

In this study we demonstrated by ELISA and western blot analysis that VEGF is present in the vitreous of patients with subfoveal neovascular membranes (SFNM) and the levels are significantly higher compared with eyes with FTMH, which is a non-ischaemic, nonneovascular disorder. This finding differs from the recent study of Aiello et $\mathrm{al}^{4}$ in which it was suggested that vitreous samples from patients with neovascular membrane had no detectable level of VEGF. However, some recent studies do suggest the involvement of VEGF in the pathogenesis of subretinal neovascularisation. Malecaze et $a l^{5}$ have been able to demonstrate, using the method of reverse transcription-polymerase chain reaction, the VEGF is expressed in samples of neovascular membranes. Immunohistochemical studies have also localised VEGF in the retinal pigment epithelial cells (RPE) and other cells surrounding the subretinal membrane in postmortem eyes and in surgically removed membranes. ${ }^{17} 18$ Although, RPE cells have been shown to synthesise and secrete VEGF in vitro and in situ ${ }^{19}$ other cellular components of the neovascular membranes such as fibroblasts or macrophages could also be a likely source of VEGF. The latter are present in the majority of active subretinal neovascular complexes and represent an inflammatory component of the disease process. ${ }^{15} 16$ In a recent report, Motokura et al ${ }^{20}$ were able to demonstrate that subretinal neovascularisation can be induced in the rat by injection of VEGF into the subretinal space.

All our patients with SFNM were young with focal abnormalities of the RPE-Bruch's membrane-choriocapillaris complex due to inflammatory or idiopathic causes. A recognised stimulus of VEGF production is inflammation, ${ }^{10}$ and three of the patients in the present study had recognisable evidence of prior choroiditis, in the form of inactive chorioretinal scars. Interestingly, two of these cases had the highest measurable levels of VEGF in the study group. Not surprisingly, the levels of VEGF found in cases with SFNM were significantly lower than those found in the diabetics 
with proliferative diabetic retinopathy. This could be explained by the fact that SFNM is a focal process whereas PDR involves very extensive areas of retinal ischaemia. The observation that VEGF is elevated in the vitreous of patients with PDR is consistent with other reports ${ }^{42122}$ but the mean concentration of VEGF is different; $37 \cdot 77 \mathrm{ng} / \mathrm{ml}$ in the present study compared with $4 \mathrm{ng} / \mathrm{ml}$ reported by Aiello et $\mathrm{al}^{4}$ and $1 \cdot 164 \mathrm{ng} / \mathrm{ml}$ reported by Adamis $e t a l .{ }^{23}$ The mean value in the present study is in line with $28 \mathrm{ng} / \mathrm{ml}$ reported by Plouet et $a l^{24}$ but is lower than $88 \mathrm{ng} / \mathrm{ml}$ reported by Malecaze et al. ${ }^{5}$ One possibility for this large variation in VEGF levels found in the different laboratories is perhaps the timing of vitreous sampling. Aqueous levels of VEGF have been reported to decrease before regression of new vessels in monkeys with iris neovascularisation. This could also account for the large variability in the vitreous VEGF levels in patients with PDR found by us and all the other workers. ${ }^{42324}$ Variations in the standard diluent, incubation time, temperature, pipetting and age of the antibody are also likely to effect the sensitivity and the measurement of VEGF by ELISA in the different laboratories. ${ }^{452324}$

Although photocoagulation is effective in preserving central vision in extrafoveal or juxtafoveal lesions ${ }^{2125-27}$ recurrences are common and frequently involve the fovea, resulting in permanent loss of vision. ${ }^{22}$ Photocoagulation treatment of subfoveal lesions is, in general, unsatisfactory with initial profound decrease in central vision. ${ }^{28}$ Subfoveal membranes can be removed by surgical techniques and restore acuity in selected cases. ${ }^{13}$ Patients with ARMD tend to fare poorly with surgery, and the best candidates seem to be those with ocular histoplasmosis or idiopathic lesions that have relatively focal areas of disease. ${ }^{14}$ The findings that elevated levels of VEGF are present in the vitreous of eyes with non-age-related subretinal neovascularisation would suggest that VEGF may be similarly involved in subretinal angiogenesis. If these results are confirmed by larger studies, further investigations on the action of VEGF in the subretinal space may lead to novel therapies with antibodies or other inhibitors of VEGF that might involve less tissue destruction and better preservation of vision than photocoagulation or surgical removal.

Presented in part at the 1995 ARVO meeting, Fort Lauderdale, FL, USA.

1 Michaelson IC. The mode of development of the vascular system of the retina, with some observations on its significance for certain retinal diseases. Trans Ophthalmol Vis Sci 1948; 68: 137-80.

2 Senger DR, Galli SJ, Dvorak AM, Perruzzi CA, Harvey VE, Dvorak HF. Tumour cells secrete a vascular permeability factor that promotes accumulation of ascites fluid. Science factor that promotes

3 Plouet J, Schilling J, Gospodarowicz D. Isolation of a newly identified endothelial cell mitogen produced by AtT-20 cells. EMBO F 1989; 8: 3807 .

4 Aiello LP, Avery RL, Arrigg PG, Keyt BA, Jampel HD, Shah ST, et al. Vascular endothelial growth factor in ocular fluid of patients with diabetic retinopathy and other retinal disorders. N Engl $\mathcal{F}$ Med 1994; 331: 1480-7.

5 Malecaze F, Clamens S, Simmore-Pinatel V, Mathis A,
Chollet P, Favard C, et al. Detection of vascular endothelial growth factor messenger RNA and vascular endothelial growth factor-like activity in proliferative endothelial growth factor-like activity in proliferative
diabetic retinopathy. Arch Ophthalmol 1994; 112: 1476-82.

6 Tischer E, Mitchel R, Hartman T, Silva M, Gospodarowicz $\mathrm{D}$, Fiddes JC, et al. The human gene for vascular endothelial growth factor: multiple protein forms are encoded through alternative exon splicing. F Biol Chem 1991; 226: 11947-54.

7 Keck PJ, Hauser SD, Krivi G, Sanzo K, Warren T, Feder J, et al. Vascular endothelial growth factor is a secreted et al. Vascular endothelial growth factor is a

8 Shaveki D, Itin A, Soffer D, Keshet E. Vascular endothelial growth factor induced by hypoxia may mediate hypoxiainitiated angiogenesis. Nature 1992; 354: 843-5.

9 Pertovaaram L, Kaipainen A, Mustonen T, Orpana A, Ferrara N, Saksela O, et al. Vascular endothelial growth factor is induced in response to transforming growth factor- $\beta$ in fibroblastic and epithelial cells. $\mathcal{F}$ Biol Chem 1994; 269: 6271-4.

10 Dvorak HF, Detmar M, Claffey KP, Nagy IA, Vander Waters L, Senger DR. Vascular permeability/vascular endothelial growth factor: an important mediator of angiogenesis in malignancy and inflammation. Int Arch angiogenesis in malignancy and immunol 1995; 107: 233-5.

11 Senger DR, Perruzzi CA, Feder J, Dvorak HF. A highly conserved vascular permeability factor secreted by a variety of human and rodent tumor cell lines. Cancer Res 1986; 446: 5629-32.

12 Miller JW, Shima DT, Tolentino M, Gragoudas ES, Ferrara N, Connolly EJ, et al. Inhibition of VEGF prevents ocular neovascularization in monkey model. Invest Ophthalmol Vis Sci 1995; 36: S401.

13 Thomas MA, Kaplan HJ. Surgical removal of subfoveal neovascularization in the presumed ocular histoplasmosis syndrome. Am f Ophthalmol 1991; 111: 1-7.

14 Gass JDM. Biomicroscopic and histopathologic considerations regarding the feasibility of surgical excision of subfoveal neovascular membranes. Am $\mathcal{F}$ Ophthalmol 1994; 118: 285-98.

15 Grossniklaus HE, Martinez JA, Brown VB, Lambert HM, Sternberg P Jr, Capone A Jr, et al. Immunohistochemical and histochemical properties of surgically excised subretinal neovascular membranes in age-related subretinal neovascular membranes in age-related macular

16 Saxe SJ, Grossniklaus HE, Lopez PF, Lambert HM, Sternberg P, L'Hernault N. Ultrastructural features of surgically excised subretinal neovascular membranes in the ocular histoplasmosis syndrome. Arch Ophthalmol 1993; 111: 88-95.

17 Dastgeib K, Li Q, Chan C-C, Roberge FG, Csaky K, Green WR. Vascular endothelial growth factor (VEGF) in neovascular age-related macular degeneration. Invest vascular age-related macular
Ophthalmol Vis Sci 1995; 36: S102.

18 Amin RH, Frank RN, Eliott D, Puklin JE. Vascular endothelial growth factor (VEGF) and basic fibroblast growth factor (bFGF) immunoreactivity in human choroidal neovascular membranes. Invest Ophthalmol Vis Sci 1995; 36: S552.

19 Adamis AP, Shima DT, Yeo KT, Brown LF, Berse B, D'Amore PA, et al. Synthesis and secretion of vascular permeability factor/vascular endothelial growth factor by human retinal pigment epithelial cells. Biochem Biophys Res Commun 1993; 193: 631-8.

20 Motokura M, Saito Y, Lim E, Chaudhry NA, Barnstable CJ, Liggett PE. Experimental model of subretinal neovascularization in rats. Invest Ophthalmol Vis Sci 1995; 36: S94.

21 Macular Photocoagulation Study Group. Krypton laser photocoagulation neovascular lesion of age-related macular degeneration: results of a randomized clinical trial. Arch Ophthalmol 1990; 108: 109-14.

22 Macular Photocoagulation Study Group. Argon laser photocoagulation for neovascular maculopathy after 5 years: results of a randomized clinical trial. Arch Ophthalmol 1991; 109: 109-14.

23 Adamis P, Miller JW, Bernal M-T, D'Amico DJ, Folkman J, Yeo T-K, et al. Increased vascular endothelial growth factor levels in the vitreous of eyes with proliferative diabetic retinopathy. Am f Ophthalmol 1994; 118: 445-50.

24 Plouet J, Chollet P, Pagot V, Chauvaud D, Korobelnik J-F, Favard C, et al. Vasculotropin/VEGF levels in the vitreous of patients with proliferative diabetic retinopathy. Invest Ophthalmol Vis Sci (Suppl) 1992; 33: 1363.

25 Macular Photocoagulation Study Group. Argon laser photocoagulation for senile macular degeneration: results of a randomized clinical trial. Arch Ophthalmol 1982; 100:
912-8. 912-8.

26 Macular Photocoagulation Study Group. Argon laser photocoagulation for ocular histoplasmosis syndrome: results of a randomized clinical trial. Arch Ophthalmol 1983; 101: 1347-57.

27 Macular Photocoagulation Study Group. Argon laser photocoagulation for idiopathic neovascularization: results of a randomized clinical trial. Arch Ophthalmol 1983; 101: 1358-61.

28 Macular Photocoagulation Study Group. Laser photocoagulation of subfoveal neovascular lesions in age-related macular degeneration: results of a randomized clinical trial. Arch Ophthalmol 1991; 109: 1220-31. 